\title{
Simulation of laser heating distribution for a thermoplastic composite: effects of AFP head parameters
}

\author{
Omar Baho $^{1}$. Gilles Ausias ${ }^{1}$ • Yves Grohens ${ }^{1}$. Julien Férec ${ }^{1}$ (D) \\ Received: 3 December 2019 / Accepted: 5 August 2020 / Published online: 2 September 2020 \\ (C) The Author(s) 2020
}

\begin{abstract}
Laser-assisted automated fiber placement (AFP) is highly suitable for an efficient production of thermoplastic-matrix composite parts, especially for aeronautic/aerospace applications. Heat input by laser heating provides many advantages such as better temperature controls and uniform heating projections. However, this laser beam distribution can be affected by the AFP head system, mainly at the roller level. In this paper, a new optico-thermal model is established to evaluate the laser energy quantity absorbed by a poly(ether ether ketone) reinforced with carbon fibers (APC-2). During the simulation process, the illuminated radiative material properties are characterized and evaluated in terms of the roller deformation, the tilt of the robot head, and the reflection phenomenon between the substrate and the incoming tape. After computing the radiative source term using a ray-tracing method, these data are used to predict the temperature distribution on both heated surfaces of the composite during the process. The results show that both the roller deformation and the tilt of head make it possible to focus the laser beam on a small area, which considerably affects the quality of the finished part. These findings demonstrate that this optico-thermal model can be used to predict numerically the insufficient heating area and thermoplastic composites heating law.
\end{abstract}

Keywords Automated fiber placement $\cdot$ Laser heating $\cdot$ Ray tracing $\cdot$ Thermoplastic composite $\cdot$ Optico-thermal analysis

\section{Introduction}

Continuous fiber reinforced thermoplastic polymer composites aim to exhibit superior properties like mechanical performance and the potential for lightweight structures. Its likely recyclability makes it a good choice for many applications, especially for aeronautic/aerospace parts. Thermoplastic-based composites allow shorter processing cycle and are also characterized by their high glass transition temperatures compared with thermosets. They have the possibility to be processed through fusion bonding which involves the application of heat and pressure at the interface [1], and therefore can be processed quickly in situ without using autoclaves [2]. Nowadays, these composites are used in a wide range of high-performance structure applications [3], and high-quality parts are produced thanks

Julien Férec

julien.ferec@univ-ubs.fr

1 UMR CNRS 6027, IRDL, Université Bretagne Sud, F-56100, Lorient, France to improvements in processing technology, more especially concerning the radiation heating [4]. For instance, the automated fiber placement (AFP) allows manufacturing composite materials out of autoclave. The AFP lays the prepreg material over flat or curved surfaces with a robotic placement head. The surfaces of both the tape and the substrate are heated, whereas a roller presses the molten surfaces at the same time in order to consolidate the prepreg, resulting in a bond.

High-power diode laser systems are used as a heat source to consolidate materials. The laser radiation is transferred through an optical fiber to the placement head on which an optical device heats both incoming tape and substrate. High temperatures induced during processing depend heavily on the process parameters, i.e., laser power, incidence laser angle, layup speed, and compaction force [5, 6]. Furthermore, the intimate contact between the plies strongly depends on the temperature of the tape and on the melting temperature of the substrate [7]. Therefore, improper control of the process parameters can lead to a strong focus of the laser beam on a small area, which can cause thermally induced degradation and other damages [8, 9]. It results in that the knowledge of the laser-power 
distribution reaching both surfaces is relevant to evaluate the total energy absorption.

Several researchers have attempted to understand the influence of the AFP process parameters on the performance of the finished part. Beyeler and Güçeri [10] developed thermal models using dioxide lasers $(P=80 \mathrm{~W}, \lambda=$ $10.6 \mu \mathrm{m})$ as a heat source for melting prepregs in a continuous manufacturing process. Thereafter, some researchers showed the importance of using a wider beam with higher laser power to improve the consolidation [11, 12]. Models describing the influence of the AFP process parameters on thermoplastics have been proposed $[5,7$, 13], for which the major emphasis concerns the incident heat flux distribution on the composite materials. For instance, Mazumdar and Hoa [13] applied a statistical method to estimate the contribution of each process parameter to the quality of the bond. They reported dominant effect of laser power (79\%) followed by tape speed $(17 \%)$ and then compaction force $(2.72 \%)$ on the bond quality. Grouve [5] investigated the influence of the laser angle on the light distribution between the incoming tape and the laminate. Specular reflection behavior was obtained by using a ray-tracing model. In the same way, Stokes-Griffin and Compston [2] showed the effect of consolidation force and laser power on bonding strength, for which the roller deformation is taken into account. In addition, some recent works showed clearly the impact of the compression and the roller deformation on the consolidation between the incoming tape and substrate $[14,15]$.

Most of the existing methods to improve AFP process do not take into account the influence of the roller deformation on the heated surfaces during the AFP process. In order to improve the accuracy in the AFP process, this research investigates how the deformable roller and reflection phenomenon under compaction force affect the laser distribution. For this purpose, a new ray-tracing algorithm is proposed to determine process parameter values such as laser power, incident laser angle, layup speed, and compaction force. Temperature distributions and thermal histories in the laminated composites are obtained as a function of these parameters, which are not adequately addressed in the literature. The paper is organized as follows. In Section 2, a semi-analytical model is developed for modeling the roller deformation in terms of the compaction force. In Section 3, a ray-tracing procedure based on the optics geometric is presented to determine the heat flux distribution on the composite by taking into account the design parameters of the roller. This flux is then injected into the thermal model presented in Section 4, which is used to estimate the temperature distribution on the bottom surface of the incoming tape and on the upper surface of the substrate. In the last Section 5, the influence of the process parameters on the laminate and incoming tape is tested and discussed.

\section{Roller deformation model}

\subsection{Problem statement}

The roller compaction plays an important role in AFP machines, as it applies a pressure field onto the tape during fiber layup. With regard to the pressure required for the consolidation, the roller (mostly made in silicone rubber) is able to deform leading to large pressure distributions and favors the development of intimate contact. However, increasing the pressure on the roller directly affects its geometric shape, which in turn influences the laser distribution in the tape and substrate. That is why it is important to take into consideration the geometric roller deformation from the beginning of heating.

Figure 1 shows a schematic illustration of a tape placement head used in AFP machines. This head uses a laser optics module to heat the thermoplastic material at a given optics incidence angle $\beta$ and laser power $P_{L}$. The temperature at the nip-point depends on the contact width $2 w$ and the angle tilt of the head $\theta$. The other main parameters are the placement velocity $V$, the diameter of the roller $R$, and the laser beam height (working distance $w_{d}$ )

\subsection{Semi-analytical model}

To find a relationship between the contact zone width $2 w$ and length deformation of the roller (as shown in Fig. 2), a commercially available silicone mono-block roller $(2 R=69 \mathrm{~mm}, 40$ Shore hardness and provided by Coriolis Composites) is used in this work. This roller is coated with $t_{p}=0.5 \mathrm{~mm}$ thickness of non-adhesive PFA (perfluo-roalkoxy), leading to considering the roller to be a heterogeneous material. A comparison with experimental measurements of a contact width $2 w$ and compression force of the roller is performed with the semi-analytical method based on contact mechanics [16].

According to Johnson [16], the half-contact width $w$ for a rectangular contact area of the roller with a flat substrate is found to be:

$w^{F}=2 \sqrt{\frac{R F \cos (\theta)}{\pi E_{e q} L}}$,

where the equivalent Young modulus is given by $E_{e q}=$ $-E_{r} E_{s} /\left(E_{r} v_{s}^{2}+E_{s} v_{r}^{2}-E_{r}-E_{s}\right) . E_{r}$ and $E_{s}$ correspond to the Young modulus for the roller and the substrate, respectively, and $v_{r}$ and $v_{s}$ are their associated Poisson ratios. $L$ is the length of the roller contact, $F$ is the applied normal load, and $R$ is the perfect radius of the roller. When 
Fig. 1 Schematic illustration of the AFP process with tilt of the head

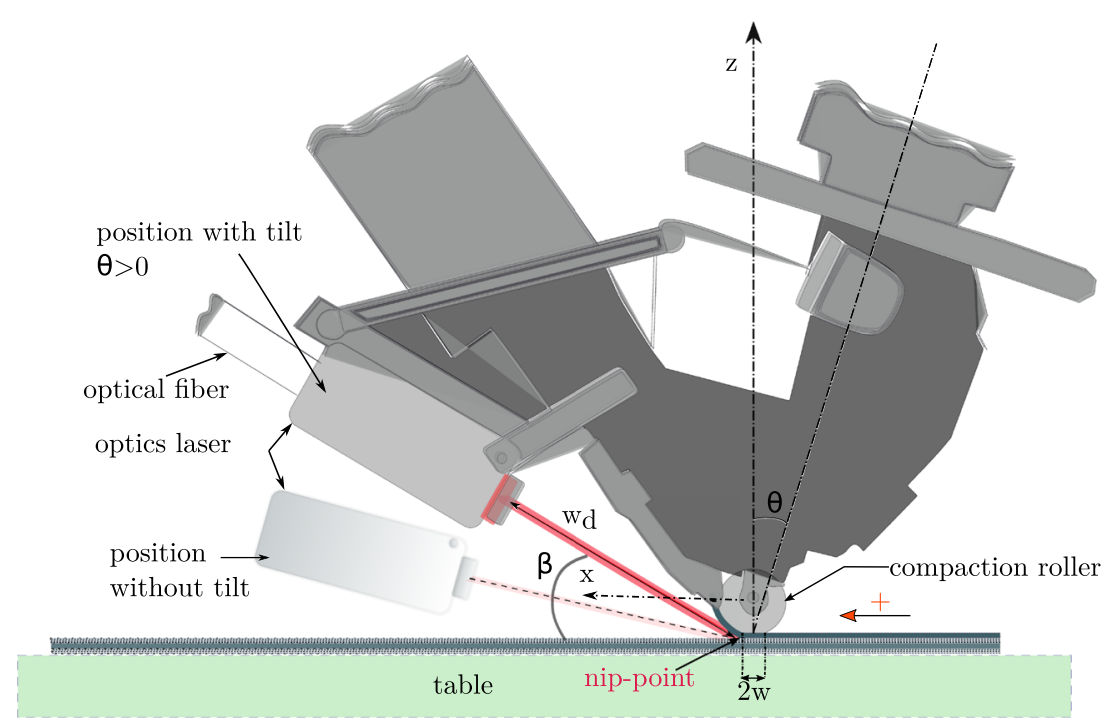

the substrate curvature is considered (as shown in Fig. 2), the radius $R$ is replaced by $\left(R \kappa_{s}+1\right) / \kappa_{s}$, where the substrate curvature $\kappa_{S}$ is given by:

$\kappa_{s}=\frac{g^{\prime \prime}(x)}{\left(1+g^{\prime}(x)\right)^{3 / 2}}$.

$g(x)$ represents the profile of the substrate. For rigid substrate, the radial deformation of the roller depends on the rectangular contact area and effective rolling radius $R_{c}$, which depends on the normal load. According to Hertz contact theory [16], the radial deformation $\delta_{r}=R-R_{c}-H_{t}$ is $[17,18]$ :

$\delta_{r}=\frac{P \cos (\theta)}{\pi} \frac{1-v_{r}^{2}}{E_{r}} \ln \left(e^{\alpha_{r} / 2} \frac{4 R}{b w^{F}}\right)$, where $\alpha_{r}=\log (2)-\left(1-v_{r}-2 v_{r}^{2}\right) /\left(1-v_{r}^{2}\right)$ [19]. The profile of the roller is then determined with the help of Eq. 4. Equations $4 \mathrm{a}$ and $\mathrm{b}$ represent the profile form of the roller in the range $z<0$, and Eq. $4 \mathrm{c}$ is obtained by assuming $R=$ constant, which means that there is no roller deformation for $z>0$ and $\forall x$.

$f_{z}^{F}(x)=\left\{\begin{array}{lr}\frac{\left(\delta_{r}-R\right)}{\left(R-w^{F}\right)^{2}} \sqrt{\left(R-w^{F}\right)^{2}-\left(x-\frac{|x|}{x} w^{F}\right)^{2}} \forall z<0 \quad(a) \\ \delta_{r}-R \\ \sqrt{R^{2}-x^{2}} & \forall z<0, \forall|x|<w^{F} \quad(b) \\ \forall z>0 & (c)\end{array}\right.$

A homogenization technique is used to estimate the effective mechanical properties of the investigated roller [20]. The relationship between the average stress tensor $\bar{\sigma}$ and the

Fig. 2 Schematic representation of the crushing for the compaction roller

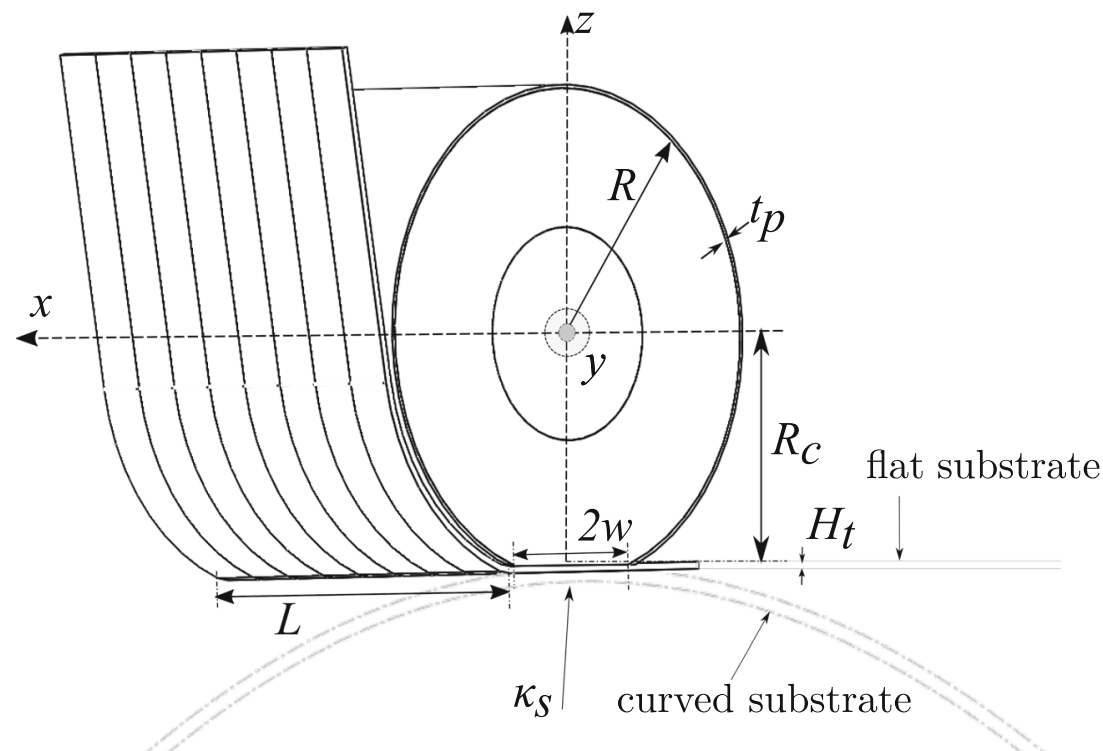


Table 1 Homogenized mechanical properties of the roller

\begin{tabular}{lllll}
\hline$E_{x}^{*}(\mathrm{MPa})$ & $E_{y}^{*}(\mathrm{MPa})$ & $G_{x z}^{*}(\mathrm{MPa})$ & $v_{x y}^{*}$ & $v_{y z}^{*}$ \\
\hline 2.821 & 3.303 & 1.130 & 0.408 & 0.460 \\
\hline
\end{tabular}

average strain tensor $\bar{\varepsilon}$ for homogeneous periodical material follows the generalized Hooke law, $\bar{\sigma}_{i j}=C_{i j k l}^{H} \bar{\varepsilon}_{k l}$, where $C_{i j k l}^{H}$ is the effective stiffness tensor of the roller. Then, the effective mechanical properties can be obtained by using the average stress and strain energy of the meso-structure under specific boundary conditions and loads.

The ABAQUS finite element software is used to identify the equivalent properties of the roller, denoted by asterisk symbols. Elasticity modulus for silicone is obtained from the relationship between Shore hardness and Young modulus [21]. Table 1 summarizes the results.

\subsection{Experimental validation}

An instrumental 8-fiber roller (R8F40SH) is used to conduct the experimental work. It consists of studying the roller crushing in a tensile/compression machine (Instron $5 \mathrm{kN}$ ), which allows measuring the radial deformation with a great precision. A camera is added to visualize directly the roller crushing in contact with a metal support. After applying the force, the contact width $2 w$ can be measured by adding

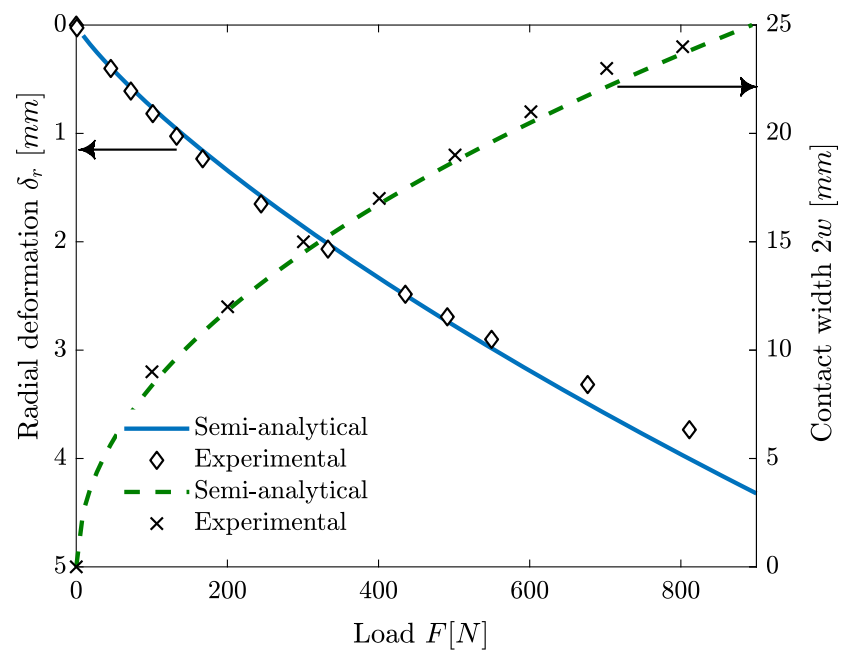

Fig. 4 Comparison of the experimental and semi-analytical results for the roller radial deformation and contact width

two thin films on both sides of the roller as shown in Fig. 3, while the radial deformation is exported directly from Instron software as a function of applied force. Various forces in the range of $F=0 N$ to $900 N$ are applied on the roller resting on a rigid flat surface. The contact width as well as the radial deformation are measured and depicted in Fig. 4.

The numerical results are also presented in Fig. 4. The comparison between both approaches shows clearly a good agreement for the radial deformation $\delta_{r}$ and the contact width $2 w$.
Fig. 3 Experimental setup (left) and visualization of the contact between the roller and the flat mold (right)
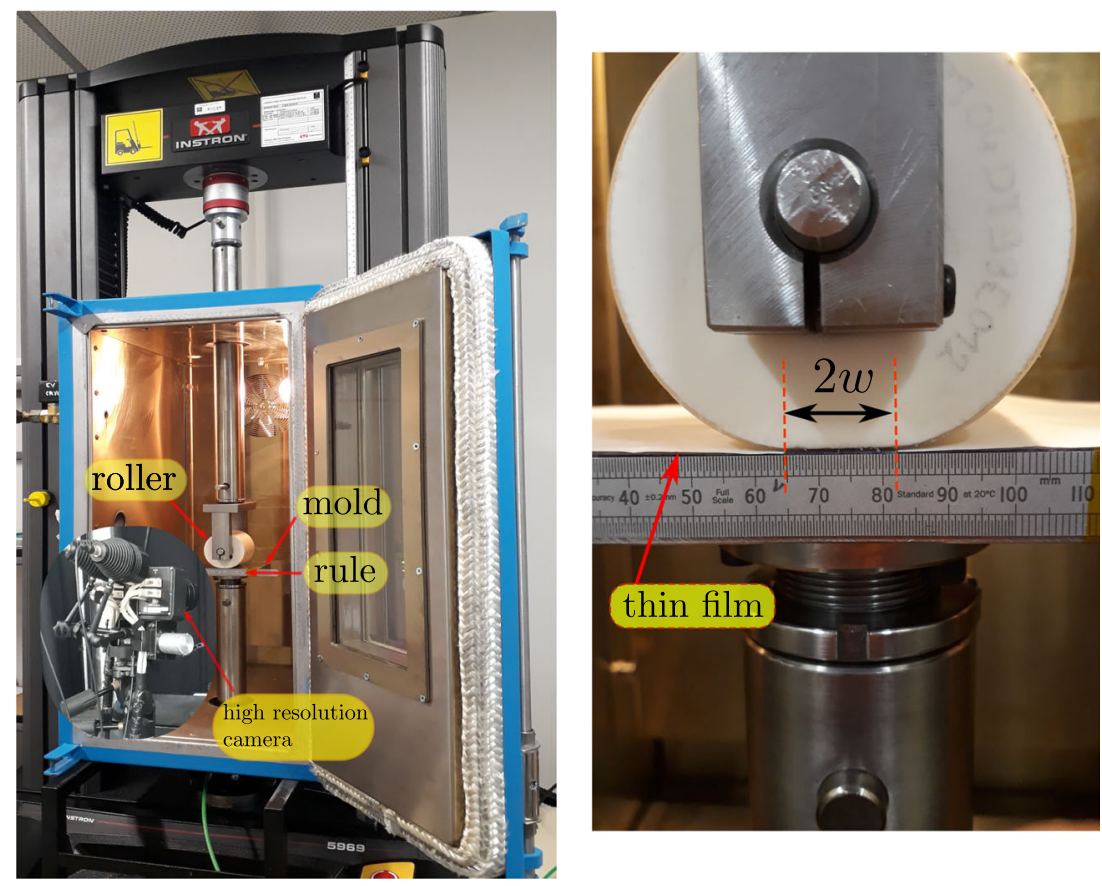


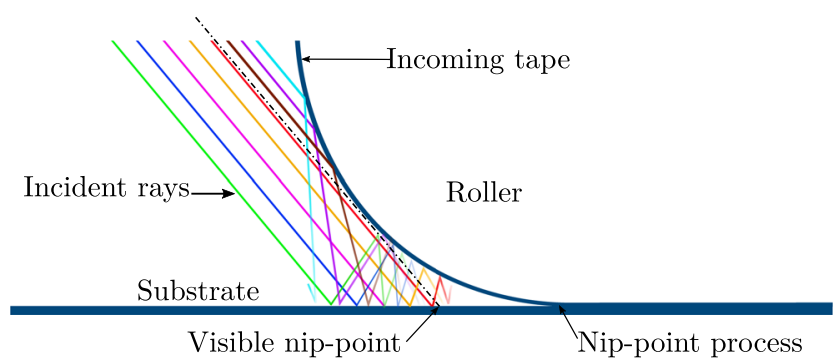

Fig. 5 Principle of an AFP process with visualization of laser reflections on the tape and on the substrate

\section{Laser heat distribution}

\subsection{Optical properties}

A simplified (2-D) ray-tracing approach is used to determine the heat flux distribution based on optical geometric. The idea is to characterize numerically the heat flux distribution on the incoming tape and substrate by taking into account the reflection of the laser light at the nippoint region. Most of the process parameters are considered such as the incident laser angle $\beta$, the laser spot size, the tilt of head $\theta$, and the compaction force on the roller $F$. In this context, the laser beam is represented by $n_{r}$ rays which are distributed with predefined incident angles. Whenever a ray encounters the substrate or the incoming tape, it is slightly deflected or reflected depending on the incident angle of the laser beam and the orientation angle of carbon fibers in the substrate, as illustrated in Fig. 5. The proportions of reflected energy for the s- and p-polarized light are given by the Fresnel coefficients $r_{s}$ and $r_{p}$, respectively.

$$
\begin{aligned}
& r_{s}=\left|\frac{n_{\text {air }} \cos (\phi)-\sqrt{(\cos (\phi))^{2} n_{\text {air }}{ }^{2}+N^{2}-n_{\text {air }}{ }^{2}}}{n_{\text {air }} \cos (\phi)+\sqrt{(\cos (\phi))^{2} n_{\text {air }}^{2}+N^{2}-n_{\text {air }}^{2}}}\right|^{2}, \\
& r_{p}=\left|\frac{-N^{2} \cos (\phi)+n_{\text {air }} \sqrt{(\cos (\phi))^{2} n_{\text {air }}{ }^{2}+N^{2}-n_{\text {air }}{ }^{2}}}{N^{2} \cos (\phi)+n_{\text {air }} \sqrt{(\cos (\phi))^{2} n_{\text {air }}{ }^{2}+N^{2}-n_{\text {air }}^{2}}}\right|^{2},
\end{aligned}
$$

Fig. 6 Schematic diagrams of the ray-tracing methodology

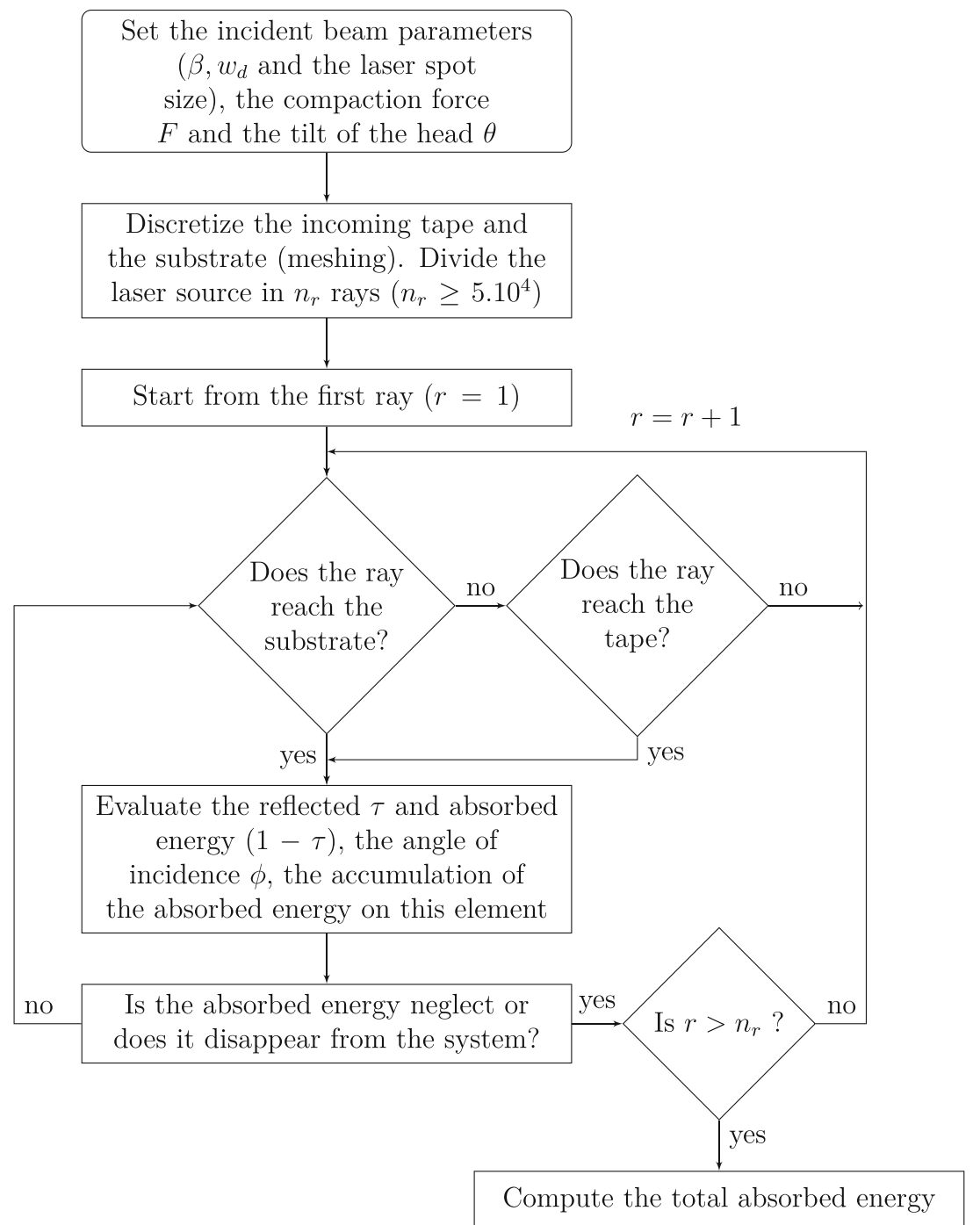




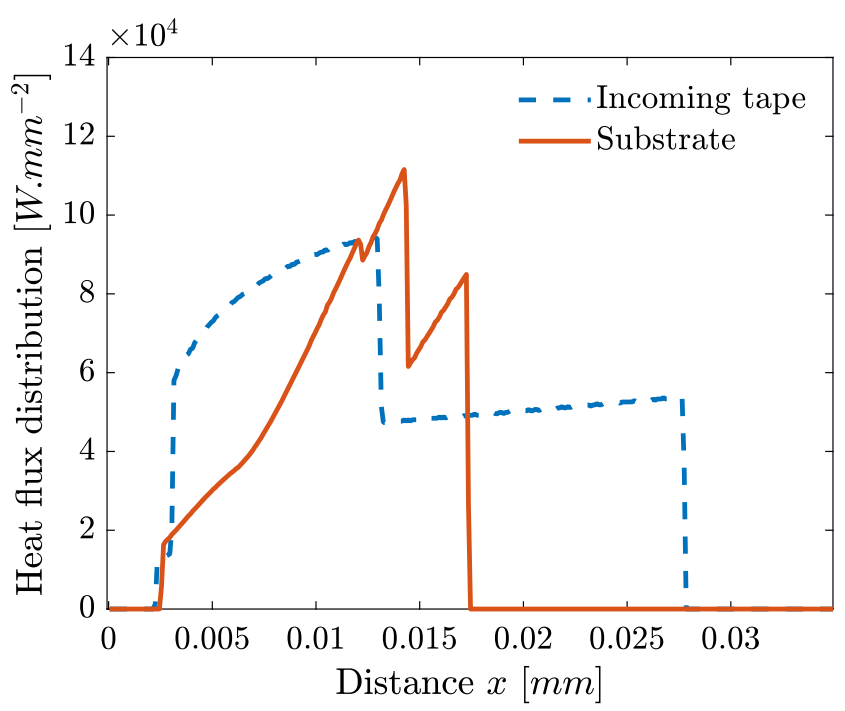

Fig. 7 Total incident heat flux on the substrate and the incoming tape. The compaction force and the tilt of the head are $F=250 \mathrm{~N}$ and $\theta=0^{\circ}$, respectively. The input laser power is $P_{L}=3 \mathrm{~kW}$ with a constant laser angle of $\beta=15.2^{\circ}$ and the placement velocity is $V=0.3 \mathrm{~m} / \mathrm{s}$. The distance from nip-point process is showed in Fig. 5

where $\phi$ is the incident angle of each ray and $n_{\text {air }}$ is the index of refraction of air. $N(\lambda)=\alpha(\lambda)-i k(\lambda)$ is the complex refractive index of APC-2, where $\alpha(\lambda)$ is the refractive index and $k(\lambda)$ is the extinction coefficient which is used to determine absorption. $N(\lambda)$ is evaluated using an homogenization method [22], which is based on the Bruggeman model, derived from the Maxwell-Garnett model [23]. The magnitude $\tau$ of the reflected energy resulting from each ray reaching the APC-2 surface is given by:

$\tau=\frac{r_{s}+r_{p}}{2}$.

The deflected rays are not considered, which implies that the partially reflected beam is neglected [24]. It is found that a sufficient number of rays $n_{r}$ for any configuration must be greater than $5 \cdot 10^{4}$.

\subsection{Ray-tracing model}

In order to evaluate the incident beam distribution on the substrate and on the incoming tape, an algorithm is proposed in Fig. 6 to take into account the variability of the resulting heat energy profile at the nip-point region. The placement head is mounted on a six-axis robot, on which is fixed an optical with a rectangular-shaped beam. The laser spot size is $56 \times 8 \mathrm{~mm}^{2}$ with a focal distance of $w_{d}=250 \mathrm{~mm}$. Based on the polarization and wavelength multiplexing techniques, the optical device generates a nearinfrared laser of wavelengths $(\lambda=980-1030 \mathrm{~nm})$ and up to $12 k W$ of power. From all these parameters and the ray-tracing algorithm, a 2-D model of laser-assisted AFP process is developed in the commercial software MATLAB. Accordingly, the heat flux distributions in the tape and substrate are characterized and evaluated in terms of the angle of incidence $\beta$, the wavelength $\lambda$, the head tilt $\theta$, and the contact width $2 w$. Figure 7 depicts the heat flux distribution in the substrate and in the incoming tape for a load of $F=250 \mathrm{~N}$, a tilt angle of $\theta=0^{\circ}$, an incident laser angle of $\beta=15.2^{\circ}$, and a laser power of $P_{L}=3 \mathrm{~kW}$.

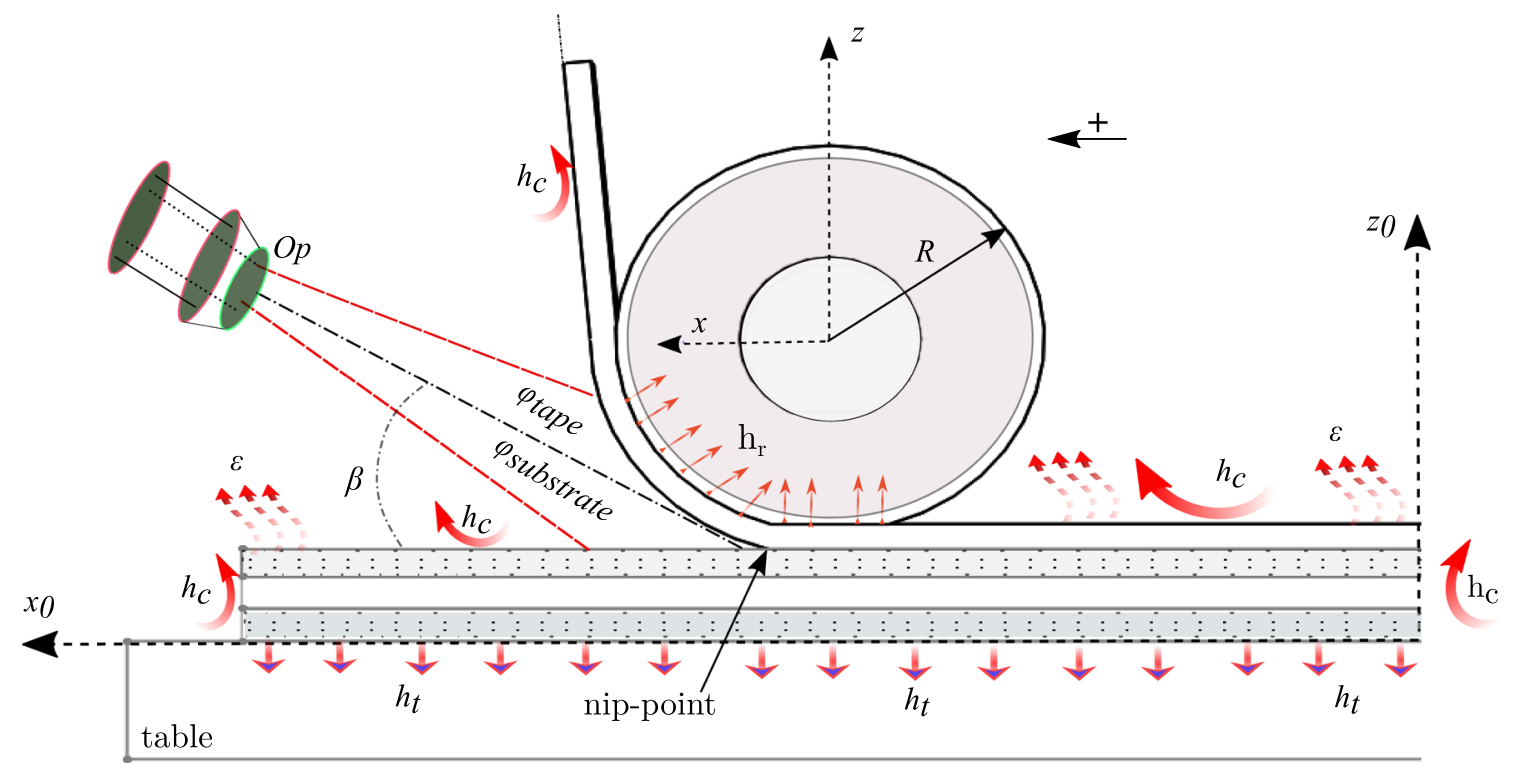

Fig. 8 Boundary conditions for the 2-D thermal analysis of tape consolidation 
Table 2 Physical properties of APC-2 at $23{ }^{\circ} \mathrm{C}$ and $400{ }^{\circ} \mathrm{C}$

\begin{tabular}{lllll}
\hline Temperature & Density & Specific heat & \multicolumn{2}{c}{ Thermal conductivity } \\
$T\left({ }^{\circ} \mathrm{C}\right)$ & $\rho\left(\mathrm{kg} / \mathrm{m}^{3}\right)$ & $C_{p}\left(\mathrm{~J} / \mathrm{kg} \cdot{ }^{\circ} \mathrm{C}\right]$ & $k_{x x}\left(\mathrm{~W} / \mathrm{m} /{ }^{\circ} \mathrm{C}\right]$ & $k_{y y}\left(\mathrm{~W} / \mathrm{m} /{ }^{\circ} \mathrm{C}\right)$ \\
\hline 23 & 1540 & 1100 & 4.92 & 0.61 \\
400 & 1524 & 1800 & 7.68 & 0.66 \\
\hline
\end{tabular}

With this configuration, the incident heat flux distribution on the tape and the incoming tape are irregular due to the reflection phenomenon between the substrate and the tape. Furthermore, there is no light able to reach the nippoint process owing to shadowing effect of the roller, which occurs from the visible nip-point (as shown in Fig. 5).

\section{Thermal model}

This analysis aims to predict the thermal distribution induced in the substrate for various process configurations.

\subsection{Heat transfer}

The governing heat transfer equation for 2-D domain can be written as:

$\rho C p \dot{T}-\operatorname{div}(\overline{\bar{K}} \cdot \overrightarrow{\operatorname{grad}} T)=0$,

in which $\overline{\bar{K}}$ is the thermal conductivity tensor, $C_{p}$ is the specific heat, and $\rho$ is the material density. Several techniques have been used to solve (7) in 3-D [25, 26], in 2D transient [27, 28], and in 2-D steady-state regimes [7, 2933], respectively. For steady-state regimes and a constant layup velocity $V$, Eq. 7 can be rewritten in the reference coordinate system linked to the roller axis as follows:

$\left.\rho C_{p} V \frac{\partial T}{\partial x}-\operatorname{div}(\overline{\bar{K}} \cdot \overrightarrow{g r a d} T)\right)=0$,

The thermal boundary conditions implemented are shown in Fig. 8. The upper surface of the substrate and the bottom surface of the incoming tape are heated by the laser heat flux distribution $\varphi_{\text {substrate }}$ and $\varphi_{\text {tape }}$, respectively, obtained from the heat flux distribution profile by using the ray-tracing method. The surfaces in contact with the ambient air are subjected to the free convection $h_{c}=$ $13 \mathrm{~W} / \mathrm{m}^{2} / K$ [34] prescribed by Newton's law $\varphi_{\text {conv }}=$ $h_{c}\left(T-T_{a m b}\right)$, in which $T_{a m b}=20{ }^{\circ} \mathrm{C}$ represents the ambient temperature. The thermal exchanges between the roller and the incoming tape, and between the substrate and the tooling are $h_{t}=436 \mathrm{~W} / \mathrm{m}^{2} / K$ and $h_{r}=$ $709 \mathrm{~W} / \mathrm{m}^{2} / K[22,35]$, respectively. The effect of radiation is also considered by using the following relationship:

$\overrightarrow{\varphi_{\text {rad }}}=h_{\text {rad }}\left(T-T_{a m b}\right) \vec{n}$

where $h_{\text {rad }}$ is the radiant heat transfer coefficient given by $h_{\text {rad }}=\sigma \varepsilon\left(T^{2}+T_{a m b}^{2}\right)\left(T+T_{a m b}\right) . \varepsilon$ is the surface emissivity taken to be 0.87 for APC-2 [22], and $\sigma=5.67 \cdot 10^{-8} \mathrm{~W} / \mathrm{m}^{2}$. $K^{4}$ is the Stefan-Boltzmann constant.

Table 2 lists the material properties used in the present work (all of them are collected from [34, 36-38]). To consider a thermal dependence, a linear variation of these properties is presumed. In addition, to take into account the orthotropic thermal conductivity, a local coordinate system is associated with each ply.

\subsection{Model implementation}

The interaction of the laser beam with a material depending on the AFP head parameters is implemented in MATLAB. The data obtained is then injected into the thermal model while keeping the same mesh of the substrate and the tape. The thermal model is performed in ABAQUS; a fully scripted procedure in Python is developed to allow
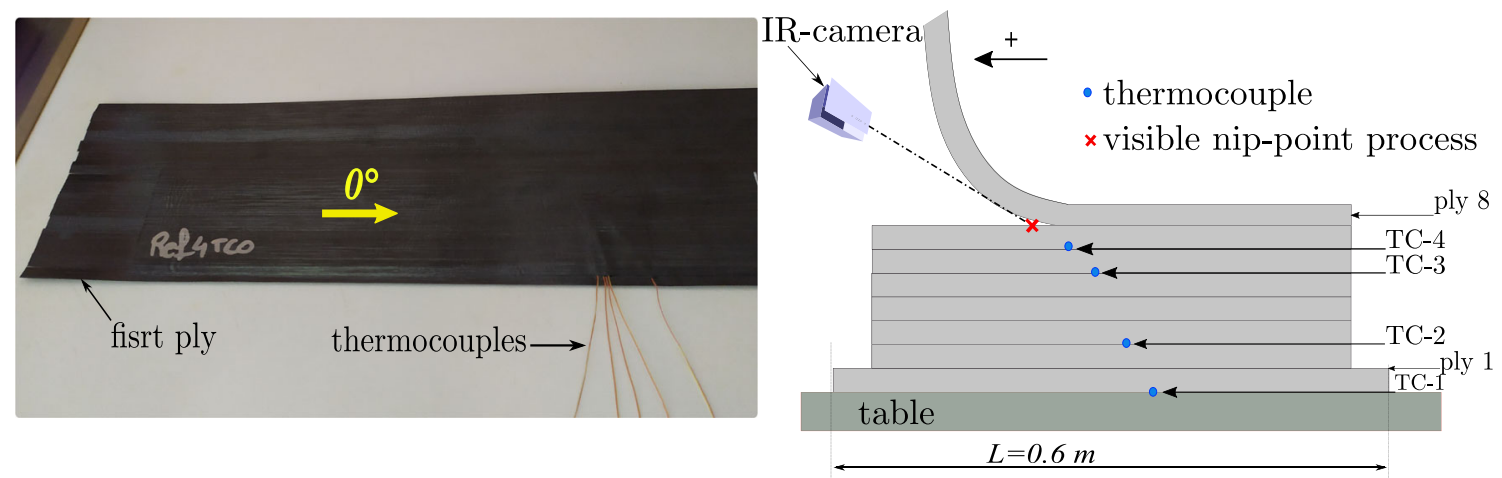

Fig. 9 Schematic of the experimental setup (left), the finished part made of $8^{\text {th }}$ layers (right) 
for fast and efficient pre- and post-processing. Parametric studies (design, material properties, number of layers, etc.) can be implemented easily by modifying the userdefined input variables. From the list of the parameters of the study and the desired number of layers in the laminate, a script generates the corresponding code and is used as input files in ABAQUS. The nonlinear heat flux distributions on the tape and substrate obtained from optical model are introduced in the thermal model as boundary conditions using user subroutine DFLUX. The thermal contact between layers is defined in GAPCON subroutine, while the evolution of boundary conditions during process is implemented in user subroutines FILM. All user subroutines are written in FORTRAN.

\subsection{Experimental validation of the optico-thermal model}

In order to validate the numerical model, a laminate made from unidirectional 8 layers is manufactured using AFP robot developed by Coriolis Composites. The goal is to measure the temperature at the visible nip-point process and the thermal history across the substrate during the lay-up of $8^{\text {th }}$ layer. The thermal acquisition through the substrate is performed using four thin K-types thermocouples $(80 \mu \mathrm{m}$ in diameter) inserted during the layup as depicted in Fig. 9. The temperature at the visible nip-point process is recorded by a IR camera mounted behind the laser optics. With regard to the numerical simulation, the $8^{\text {th }}$ layup over the laminate is carried out by injecting directly the data from Fig. 7 into the thermal model. The carbon fiber orientation for the incoming tape and the laminate is fixed at $0^{\circ}$ with respect to the laser beam direction. The half-contact width obtained is $w=6.63 \mathrm{~mm}$ for $F=250 \mathrm{~N}$. Then, for the placement velocity of $V=0.3 \mathrm{~m} \cdot \mathrm{s}^{-1}$,

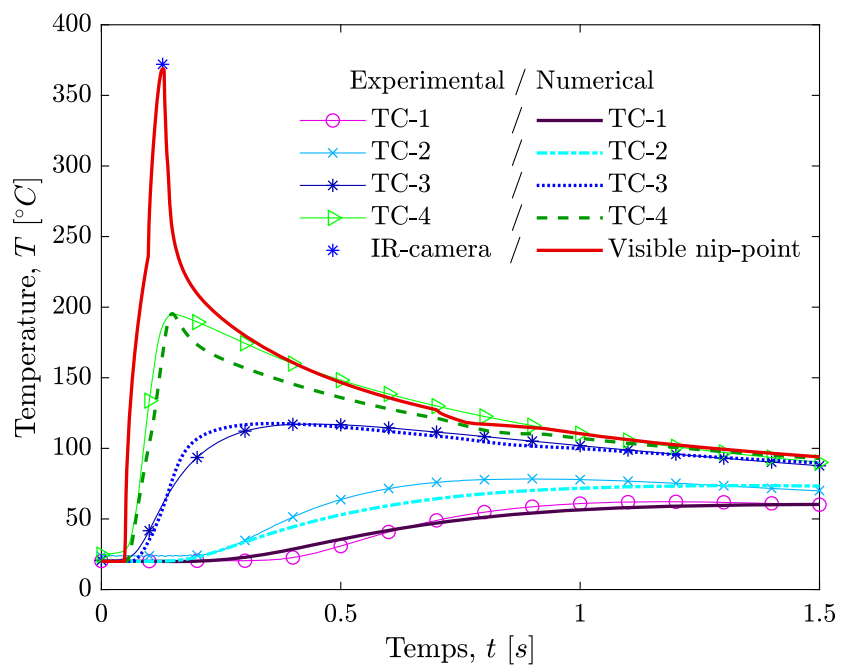

Fig. 10 Measured and predicted thermal history in the laminate during the deposition of the $8^{\text {th }}$ layer the thermal history in the substrate is determined by a transient analysis and compared with the experimental data as shown in Fig. 10. It is shown that the numerical predictions of thermal history in the substrate are in good agreement with the experimental measurements in terms of the timing and maximum temperature. On the other hand, the maximum average temperature value measured by IR camera during the layup is $372.4^{\circ} \mathrm{C}$, which is approximately close to the maximum temperature obtained numerically on the top substrate surface (Fig. 10). This temperature is greater than the melting temperature of PEEK $\left(349^{\circ} \mathrm{C}\right)$. In addition, the cooling step shows a good agreement between the simulation and the experimental data despite a small difference induced near the visible nip-point process due to the presence of the shaded region. The finished part of this simulation is shown in Fig. 9 (left).
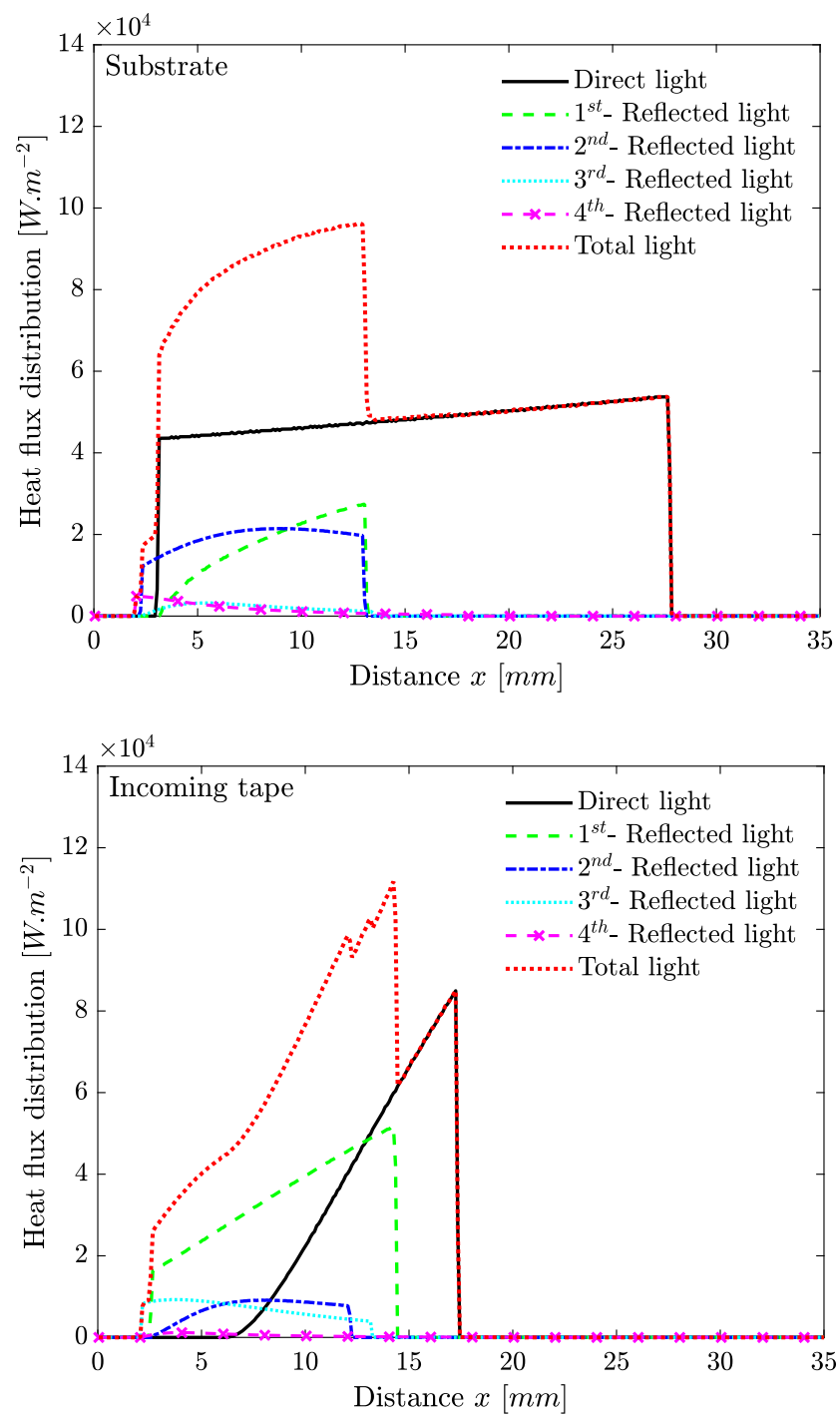

Fig. 11 Effect of the light reflection on the heat flux distribution between incoming tape and substrate $\left(F=250 \mathrm{~N}, \theta=0^{\circ}, P_{L}=\right.$ $3 \mathrm{~kW}, V=0.3 \mathrm{~m} / \mathrm{s}$, and $\beta=15.2^{\circ}$ ) 


\section{Influence of process parameters}

In order to understand the influence of the process parameters, a parametric study is carried out without considering the interaction between these parameters. The optico-thermal model is used to highlight the effect of the process parameters on the heat flux distribution between the incoming tape and the substrate, then on the associated temperatures near the nip-point process.

\subsection{Effect of the reflected light}

Figure 11 demonstrates the impact of the reflection on the heat flux distribution between the tape and the substrate, as well as on the thermal history near the nip-point process. The graph likewise shows that the absorption of the reflected ray is negligible after three reflections from
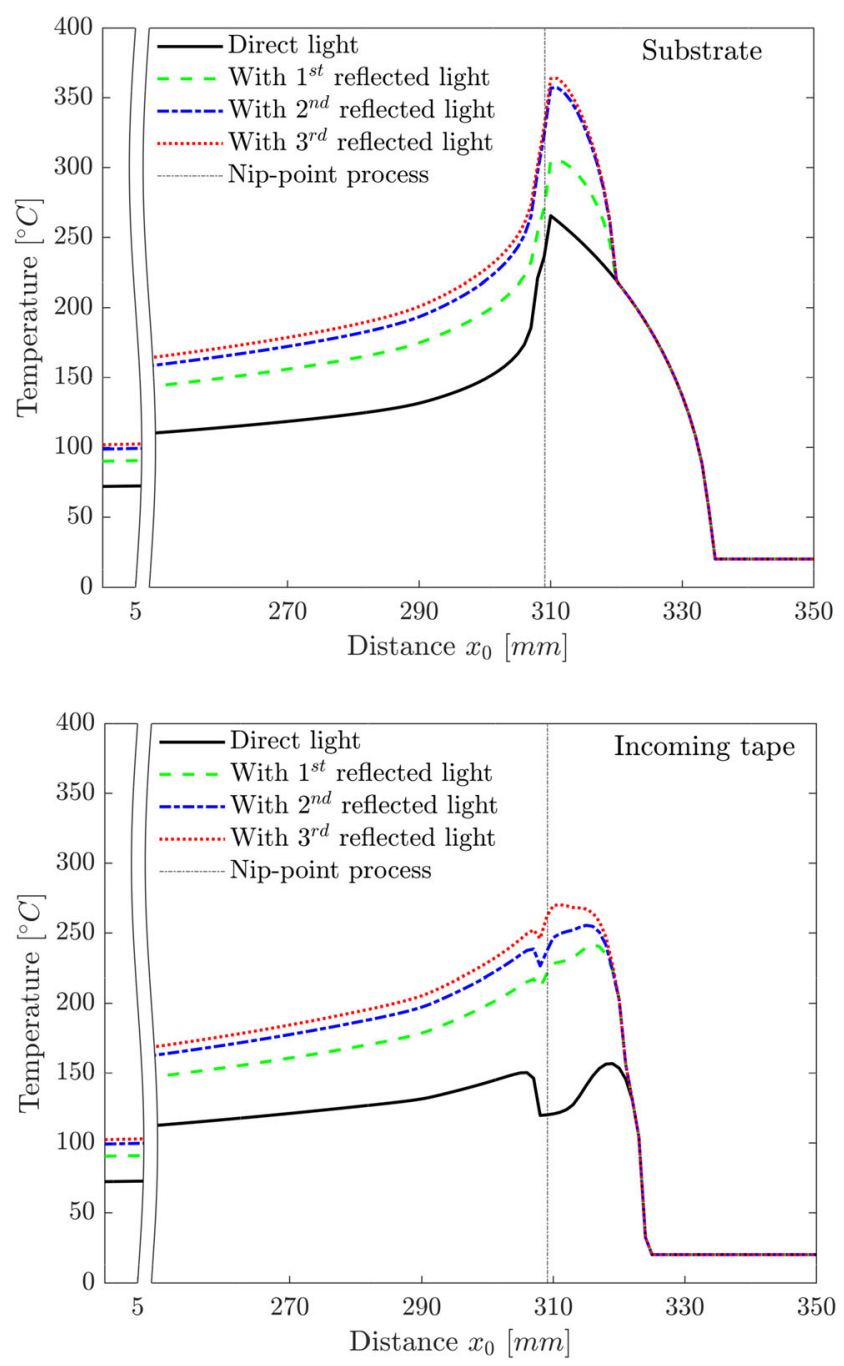

Fig. 12 Temperature profiles in the incoming tape and the substrate according to the number of reflections considered $(F=250 \mathrm{~N}$, $\theta=0^{\circ}, P_{L}=3 \mathrm{~kW}, V=0.3 \mathrm{~m} / \mathrm{s}$, and $\beta=15.2^{\circ}$ ) the substrate or the incoming tape. On the other hand, it is found that the loss of laser heat flux is $38 \%$ if the reflection phenomenon is neglected, $19 \%$ for the approximation of the first reflection used by Le Louët [39], and 6\% for the second reflection as considered by Grouve [5], while the third reflection is taken into account the loss of laser heat is $2 \%$. In addition, a shadow area is clearly visible in the incoming tape for direct light. This shadow zone is then covered by the second and third reflected lights. The thermal model indicates that the maximum temperature without taking into account the reflected light (direct light) is $254{ }^{\circ} \mathrm{C}$ in the substrate and $154{ }^{\circ} \mathrm{C}$ in the tape (see Fig. 12). However, these maximum temperatures increase depending on the number of reflected lights for both the substrate and the incoming tape. Beyond the third reflected
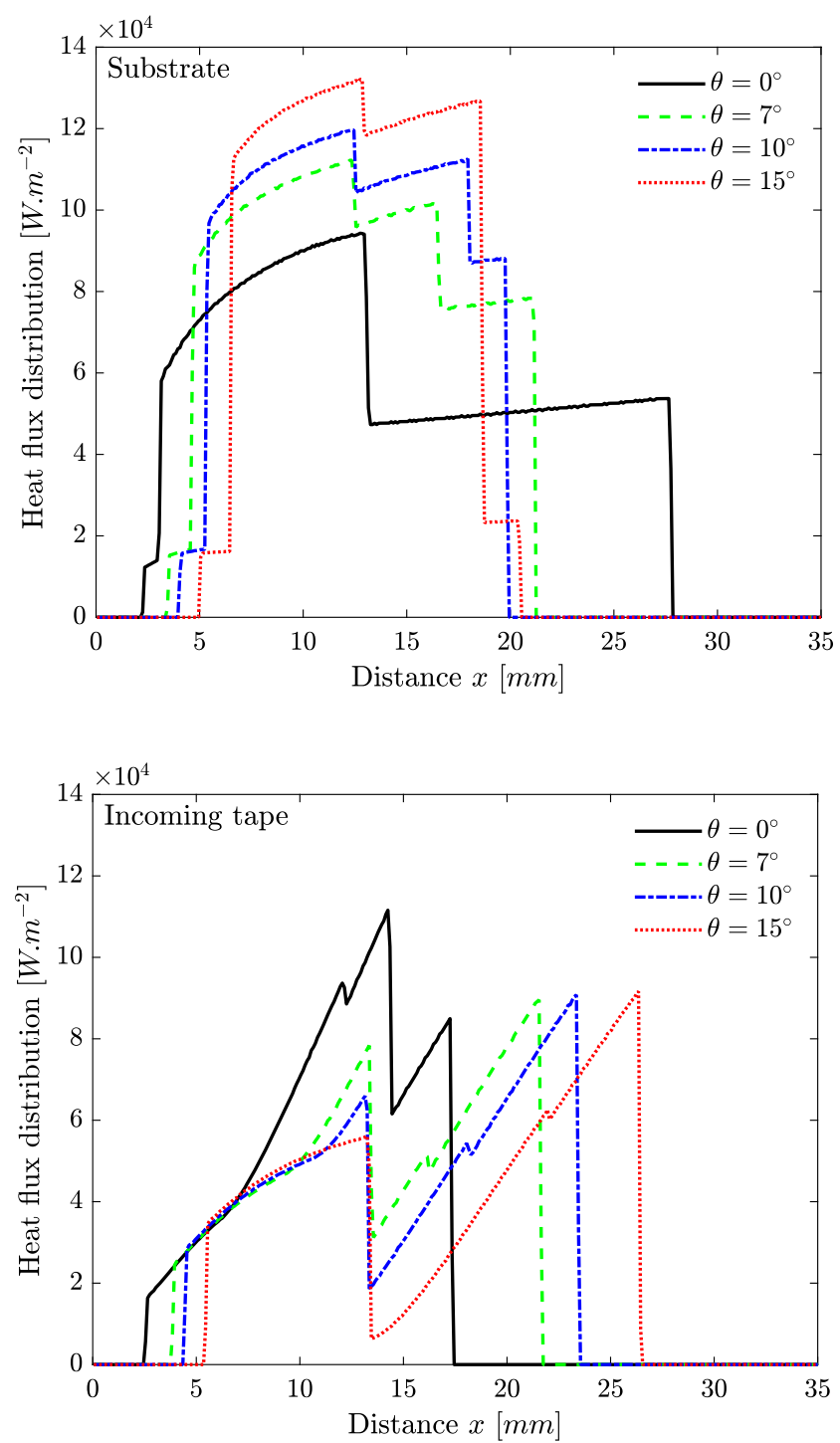

Fig. 13 Incident heat flux distribution on the tape and on the substrate with varying the tilt angle $\theta\left(F=250 \mathrm{~N}, P_{L}=3 \mathrm{~kW}, V=0.3 \mathrm{~m} / \mathrm{s}\right.$, and $\beta=15.2^{\circ}$ ). All the reflected lights are taken into account 
light, the maximum temperatures remain constant. By considering these reflected lights, the temperature increases by $45 \%$ for the incoming tape and by $75 \%$ for the substrate, respectively. This clearly demonstrates the influence of reflection phenomena on the thermal history.

\subsection{Effect of the tilt angle}

Figures 13 and 14 show the influence of the head tilt angle on the total heat flux distributions in the substrate and the incoming tape by taking into account the roller deformation. The variation of the tilt angle from $\theta=0^{\circ}$ to $15^{\circ}$ reduces the illuminated surface and increases the heat flux distribution on the substrate. Moreover, the maximum temperature near the nip-point process increases with increasing tilt angle as indicated in the thermal history results in Fig. 14. On the
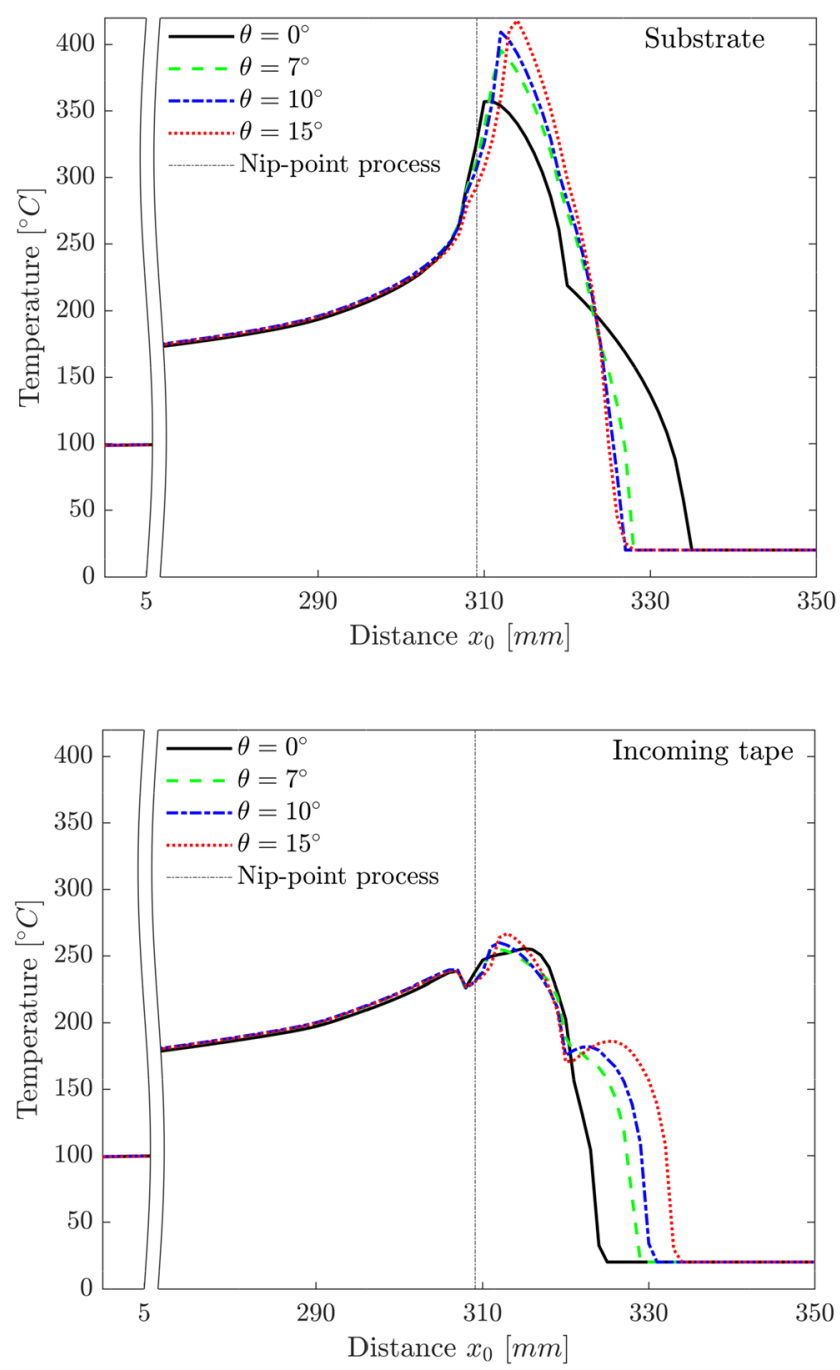

Fig. 14 Temperature profiles between the incoming tape and the substrate with varying the tilt angle $\theta\left(F=250 \mathrm{~N}, P_{L}=3 \mathrm{~kW}\right.$, $V=0.3 \mathrm{~m} / \mathrm{s}$, and $\beta=15.2^{\circ}$ ). All the reflected lights are taken into account other hand, the increase of the tilt angle has the opposite effect on the incoming tape and causes a great fluctuation in the heat flux distribution, accompanied by a decrease of the tape temperature. In addition, the larger the tilt angle, the greater the distance from the visible point due to the shadow area that the direct light does not reach, which increases with increasing tilt angle.

\subsection{Effect of the compaction force}

The influence of the load $F$ is depicted in Fig. 15, which illustrates the contribution to the total heat flux distribution due to the roller deformation. It is clear that increasing the compaction force reduces the lighting area in the incoming tape. Thus, between the compaction forces equal to
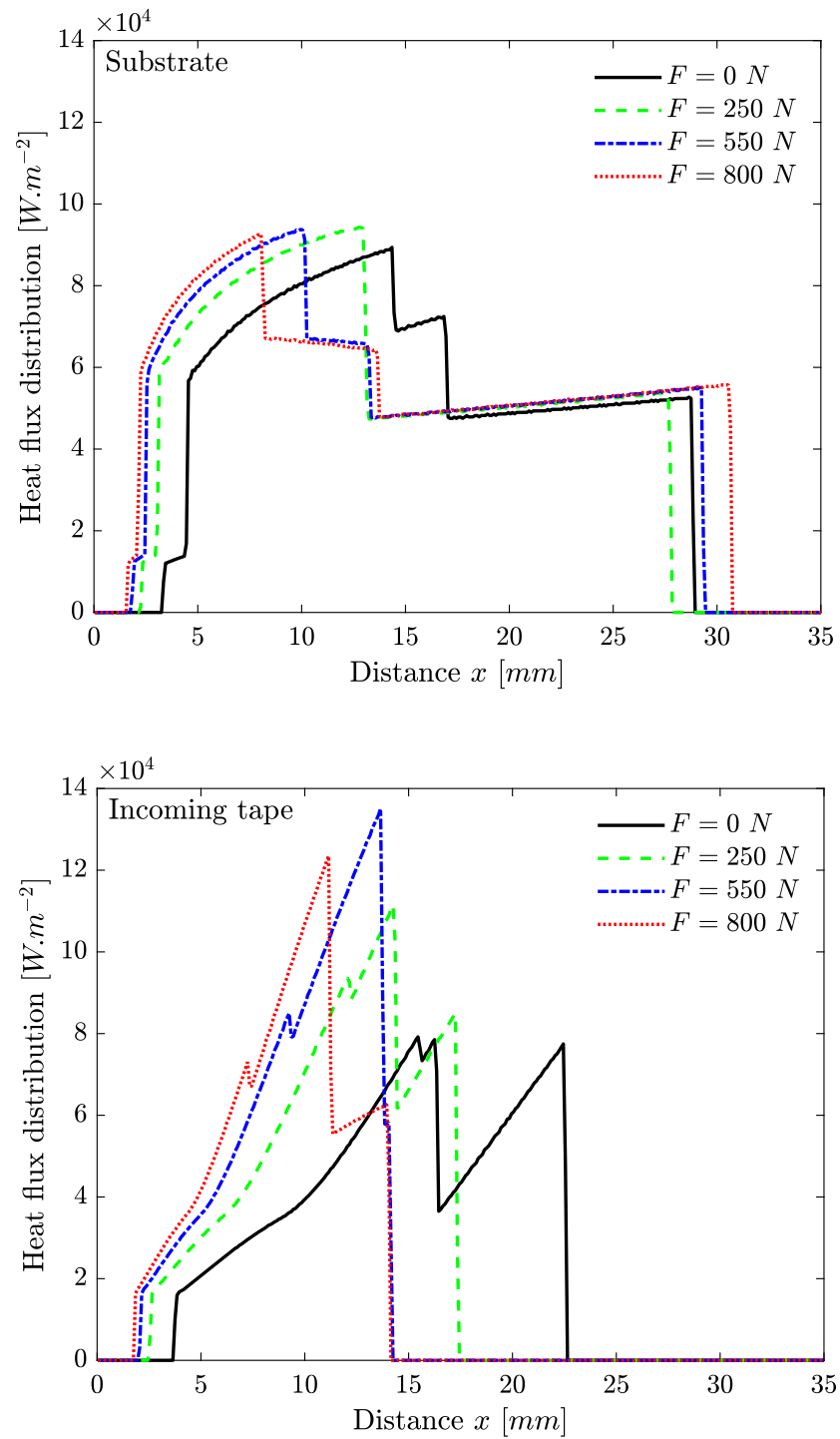

Fig. 15 Impact of load variation on the light distribution in the incoming tape and the substrate $\left(\theta=0^{\circ}, P_{L}=3 \mathrm{~kW}, V=0.3 \mathrm{~m} / \mathrm{s}\right.$, and $\beta=15.2^{\circ}$ ) 

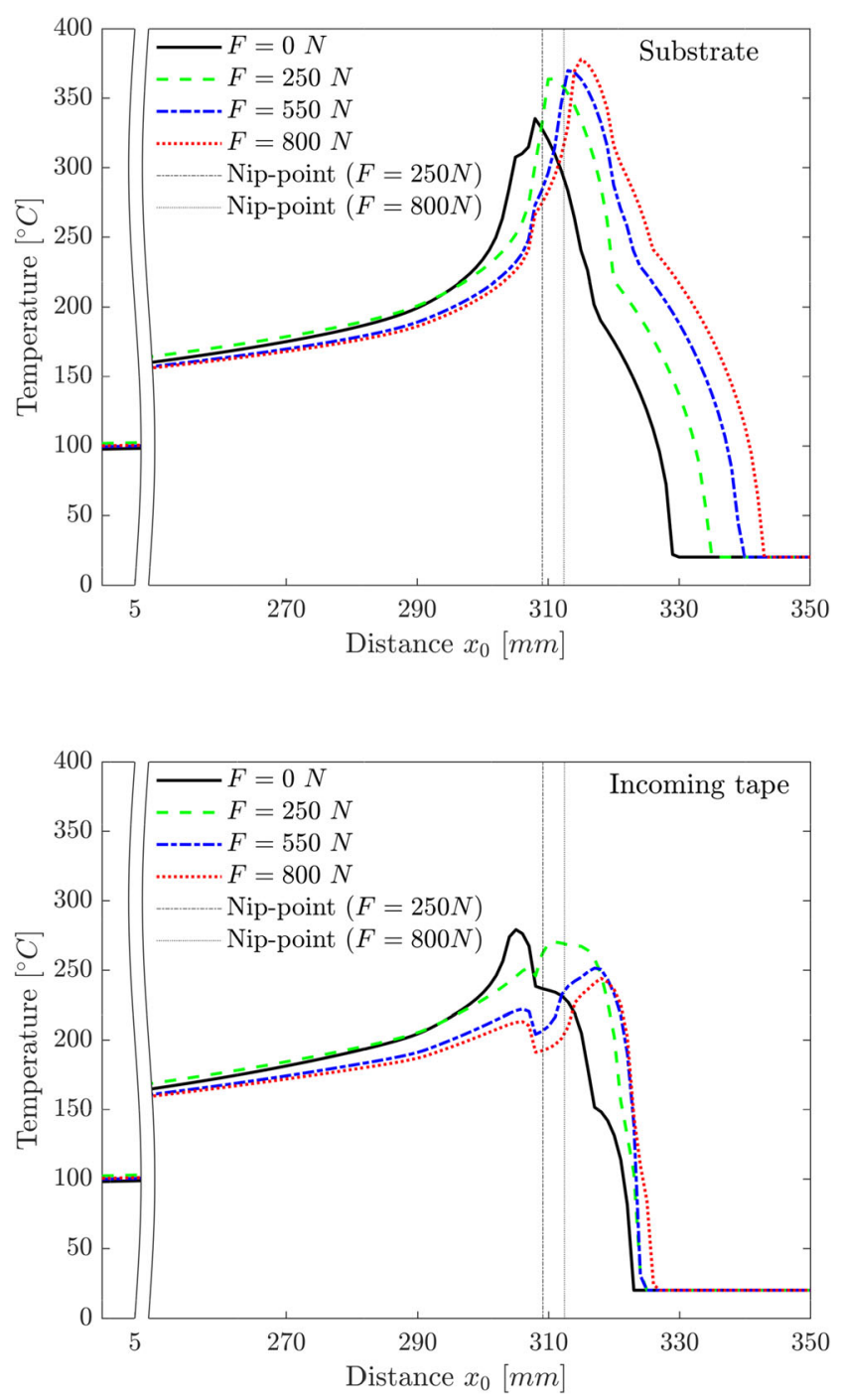

Fig. 16 Temperature profiles in the lower surface of the incoming tape and in the upper surface of the substrate under different loads $F$ $\left(\theta=0^{\circ}, P_{L}=3 \mathrm{~kW}, V=0.3 \mathrm{~m} / \mathrm{s}\right.$ and $\left.\beta=15.2^{\circ}\right)$

$F=0 N$ and $800 N$, a decrease of $14 \%$ is recorded on the maximum temperature. On the other hand, Fig. 16 shows that the greater the compaction force on the roller, the lower the temperature in upper surface of the substrate. Thereafter, the variation of the compaction force from $F=0$ to $800 \mathrm{~N}$ increases the maximum temperature of nearly $12 \%$.

\section{Conclusion}

It may be noticed that the heat flux distribution on both substrate and tape is dependent on the roller deformation and the tilt angle of the robot head. The results achieved show that an increase in tilt angle and compaction force reduces the light area and increases the heat distribution. This can lead to thermal degradation of thermoplastic polymers. Also, it is found that the reflection of rays has a significant influence on the predicted thermal history, which increases with increasing reflected light until the third reflection for APC-2. Since the compaction force is predefined to obtain a better consolidation, the elasticity properties and the design of the roller should be defined according to a good laser beam distribution. This can be appropriately predicted by the model.

Finally, the main advantage of the proposed thermooptical model is to control the heat flux distribution near the nip-point in order to prevent the laser beam focus on a small area. In addition, the interfacial thermal history in the tape and in the substrate is obtained as a function of the processing parameters. This may be very useful for establishing the heating law of the APC-2 or for another material by modifying the optical and thermal properties. Another importance of this work is to assist in the study of the sensitivity of the configuration parameters during the process.

Acknowledgments The authors wish to thank K. Henry and Y.M. Corre at ComposiTIC lab for valuable helps and fruitful discussions.

Funding The research leading to these results has received funding from the European Union's Horizon 2020 research and innovation programme under Grant Agreement No 723309.

Open Access This article is licensed under a Creative Commons Attribution 4.0 International License, which permits use, sharing, adaptation, distribution and reproduction in any medium or format, as long as you give appropriate credit to the original author(s) and the source, provide a link to the Creative Commons licence, and indicate if changes were made. The images or other third party material in this article are included in the article's Creative Commons licence, unless indicated otherwise in a credit line to the material. If material is not included in the article's Creative Commons licence and your intended use is not permitted by statutory regulation or exceeds the permitted use, you will need to obtain permission directly from the copyright holder. To view a copy of this licence, visit http:// creativecommonshorg/licenses/by/4.0/.

\section{References}

1. Yousefpour A, Hojjati M, Immarigeon J-P (2004) Fusion bonding/welding of thermoplastic composites. J Thermoplast Compos Mater 17(4):303-341. https://doi.org/10.1177/0892705704045 187

2. Stokes-Griffin CM, Compston P (2016) Investigation of sub-melt temperature bonding of carbon-fibre/PEEK in an automated laser tape placement process. Compos A: Appl Sci Manuf 84:17-25. https://doi.org/10.1016/j.compositesa.2015.12.019

3. Frketic J, Dickens T, Ramakrishnan S (2017) Automated manufacturing and processing of fiber-reinforced polymer (FRP) composites: an additive review of contemporary and modern techniques for advanced materials manufacturing. Addit Manuf 14:69-86. https://doi.org/10.1016/j.addma.2017.01.003

4. Lukaszewicz DH-JA, Ward C, Potter KD (2012) The engineering aspects of automated prepreg layup: History, present and future. 
Compos B Eng 43(3):997-1009. https://doi.org/10.1016/j.compo sitesb.2011.12.003

5. Grouve W (2012) Weld strength of laser-assisted tape-placed thermoplastic composites. Ph.D. Thesis, University of Twente, Enschede. https://doi.org/10.3990/1.9789036533928

6. Yassin K, Hojjati M (2018) Processing of thermoplastic matrix composites through automated fiber placement and tape laying methods: a review. J Thermoplast Compos Mater 31(12):16761725. https://doi.org/10.1177/0892705717738305

7. Stokes-Griffin CM, Compston P, Matuszyk TI, Cardew-Hall MJ (2015) Thermal modelling of the laser-assisted thermoplastic tape placement process. J Thermoplast Compos Mater 28(10):14451462. https://doi.org/10.1177/0892705713513285

8. Dolo G, Férec J, Cartié D, Grohens Y, Ausias G (2017) Model for thermal degradation of carbon fiber filled poly(ether ether ketone). Polym Degrad Stab 143:20-25. https://doi.org/10.1016/j.polymde gradstab.2017.06.006

9. Yalukova O, Sárady I (2006) Investigation of interaction mechanisms in laser drilling of thermoplastic and thermoset polymers using different wavelengths. Compos Sci Technol 66(10):12891296. https://doi.org/10.1016/j.compscitech.2005.11.002

10. Beyeler EP, Güçeri SI (1988) Thermal analysis of laser-assisted thermoplastic-matrix composite tape consolidation. J Heat Transf 110(2):424-430. https://doi.org/10.1115/1.3250502

11. Rosselli F, Santare MH (1997) Comparison of the short beam shear (SBS) and interlaminar shear device (ISD) tests. Compos A: Appl Sci Manuf 28(6):587-594. https://doi.org/10.1016/s1359835x(97)00009-2

12. Agarwal V, Mccullough RL, Schultz JM (1996) The thermoplastic laser-assisted consolidation process-mechanical and microstructure characterization. J Thermoplast Compos Mater 9(4):365-380. https://doi.org/10.1177/089270579600900405

13. Mazumdar SK, Hoa SV (1995) Application of Taguchi method for process enhancement of on-line consolidation technique. Composites 26(9):669-673. https://doi.org/10.1016/0010-4361(95)98 916-9

14. Jiang J, He Y, Ke Y (2019) Pressure distribution for automated fiber placement and design optimization of compaction rollers. J Reinf Plast Compos 38(18):860-870. https://doi.org/10.1177/073 1684419850896

15. Cheng J, Zhao D, Liu K, Wang Y, Chen H (2018) Modeling and impact analysis on contact characteristic of the compaction roller for composite automated placement. J Reinf Plast Compos 37(23):1418-1432. https://doi.org/10.1177/0731684418798151

16. Johnson KL (1987) Contact mechanics. Cambridge university press, Cambridge

17. Jurkiewicz A, Pyr'yev Y (2011) Compression of two rollers in sheet-fed offset printing machine. Acta mechanica et automatica 5(4):58-61

18. Jurkiewicz A, Pawlikowski M, Pyr’yev Y (2017) Analytical, numerical and experimental analysis of the relationship between two rollers axes distance and the contact zone. Int $\mathrm{J}$ Mech Sci 131-132:722-727. https://doi.org/10.1016/j.ijmecsci.2017.07. 030

19. Petrusevich AI (1950) Contact stresses, deformations, and contact hydrodynamic theory of lubrication, Extended abstract of doctoral (Tech.) dissertation, Imash, Moscow, Russia

20. Barbero EJ (2013) Finite element analysis of composite materials using abaqus ${ }^{\mathrm{TM}}$. CRC Press, Boca Raton

21. Gent AN (1958) On the relation between indentation hardness and young's modulus. Rubber Chem Technol 31(4):896-906. https://doi.org/10.5254/1.3542351
22. Dolo G (2017) Étude expérimentale et modélisation du procédé de placement de fibres avec chauffe laser. Ph.D. Thesis, Université Bretagne Sud, Lorient

23. Farooq M, Hutchins MG (2002) Optical properties of higher and lower refractive index composites in solar selective coatings. Sol Energy Mater Sol Cells 71(1):73-83. https://doi.org/10.1016/s09 27-0248(01)00045-9

24. Kollmannsberger A, Lichtinger R, Hohenester F, Ebel C, Drechsler K (2018) Numerical analysis of the temperature profile during the laser-assisted automated fiber placement of CFRP tapes with thermoplastic matrix. J Thermoplast Compos Mater 31(12):1563-1586. https://doi.org/10.1177/0892705717738304

25. Toso YMP (2003) Effective automated tape winding process with on-line bonding under transient thermal conditions. Ph.D. Thesis, ETH Zürich, Zürich

26. Hassan N, Thompson JE, Batra RC, Hulcher AB, Song X, Loos AC (2005) A heat transfer analysis of the fiber placement composite manufacturing process. J Reinf Plast Compos 24(8):869-888. https://doi.org/10.1177/0731684405047773

27. Shih P-J (1997) On-line consolidation of thermoplastic composites. Ph.D. Thesis, Virginia Tech, Blacksburg

28. Mantell SC, Springer GS (1992) Manufacturing process models for thermoplastic composites. J Compos Mater 26(16):23482377. https://doi.org/10.1177/002199839202601602

29. Agarwal V, Güçeri SI, Mccullough RL, Schultz JM (1992) Thermal characterization of the laser-assisted consolidation process. J Thermoplast Compos Mater 5(2):115-135. https://doi.org/10.11 77/089270579200500203

30. Pitchumani R, Ranganathan S, Don RC, Gillespie JW, Lamontia MA (1996) Analysis of transport phenomena governing interfacial bonding and void dynamics during thermoplastic tow-placement. Int J Heat Mass Transfer 39(9):1883-1897. https://doi.org/10.10 16/0017-9310(95)00271-5

31. Nejhad MNG, Cope RD, Güceri SI (1991) Thermal analysis of insitu thermoplastic composite tape laying. J Thermoplast Compos Mater 4(1):20-45. https://doi.org/10.1177/089270579100400102

32. Khan MA, Schledjewski R (2009) Influencing factors for an online consolidating thermoplastic tape placement process. In: Processing 17th international conference on composite materials, pp 27-31

33. Sonmez FO, Hahn HT (1997) Modeling of heat transfer and crystallization in thermoplastic composite tape placement process. J Thermoplast Compos Mater 10(3):198-240. https://doi.org/10. $1177 / 089270579701000301$

34. Nicodeau C (2005) Modélisation du soudage en continu de composites à matrice thermoplastique. Ph.D. Thesis, ENSAM, Paris

35. Levy A, Heider D, Tierney J, Gillespie JW (2013) Inter-layer thermal contact resistance evolution with the degree of intimate contact in the processing of thermoplastic composite laminates. J Compos Mater 48(4):491-503. https://doi.org/10.1177/00219983 13476318

36. Lamèthe J-F (2004) Etude de l'adhésion de composites thermoplastiques semi-cristallins; application à la mise en oeuvre par soudure. Ph.D. Thesis, Université Pierre et Marie Curie-Paris VI, Paris

37. Ageorges C, Ye L, Mai Y-W, Hou M (1998) Characteristics of resistance welding of lap shear coupons.: Part ii. consolidation. Compos A: Appl Sci Manuf 29(8):911-919. https://doi.org/10. 1016/s1359-835x(98)00023-2

38. Cogswell FN (2013) Thermoplastic aromatic polymer composites: a study of the structure, processing and properties of carbon fibre 
reinforced polyetheretherketone and related materials. Elsevier, Amsterdam

39. Le Louët V (2018) Etude du comportement thermique de bandes préimprégnées au cours du procédé de fabrication
AFP avec chauffage laser. Ph.D. Thesis, Université de Nantes, NANTES

Publisher's note Springer Nature remains neutral with regard to jurisdictional claims in published maps and institutional affiliations. 